\title{
Increased Persistence of Beauveria bassiana Spore Viability Under High Ultraviolet-blocking Greenhouse Plastic
}

\author{
H.S. Costa \\ Department of Entomology, University of California, Riverside, CA 92521 \\ K.L. Robb, and C.A. Wilen \\ University of California Cooperative Extension, 5555 Overland Avenue, \\ Building 4, San Diego, CA 92123
}

Additional index words. biological control, microbial control, pest management

\begin{abstract}
A field study was conducted to assess the effect of various commercially available polyethylene plastic greenhouse coverings on the persistence of viable spores of the microbial insecticide Beauveria bassiana. Selected coverings blocked the transmission of UV light with wavelengths of $360 \mathrm{~nm}$ and below or $380 \mathrm{~nm}$ and below. Two coverings also contained an infrared blocking component. A commercial formulation of $B$. bassiana was applied for 3 consecutive weeks to plants growing in the plastic covered hoop houses. The percentage of viable spores was calculated up to 13 days after the final application. The persistence of viable $B$. bassiana spores was significantly longer under the plastic that blocked a greater portion of the UV spectrum $(<380 \mathrm{~nm})$ than the plastics that only blocked UV wavelengths below $360 \mathrm{~nm}$. One week after application, percentage of spore germination was at least twice as high under the $<380 \mathrm{~nm}$ blocking plastic compared to $<360 \mathrm{~nm}$ blocking plastics.
\end{abstract}

Most greenhouse polyethylene plastic films contain ultraviolet (UV) light-blocking components to prolong the life of the material while maintaining transmission of photosynthetically active radiation $(P A R)$. Many greenhouse plastics on the market block transmission of the majority of UV light with wavelengths of $360 \mathrm{~nm}$ or less $(<360 \mathrm{~nm})$. However, there are also several polyethylene greenhouse film products on the market that have been specifically developed to block transmission of UV light with wavelengths of $380 \mathrm{~nm}$ or less $(<380 \mathrm{~nm})$. Examples of full transmission spectra for various UV-blocking plastics were reported previously (Antignus et al., 1996, Costa et al., 1999).

The $<380 \mathrm{~nm}$ plastics are often marketed as having insect and disease reducing benefits. It has been reported that some plant fungal pathogens, such as Botrytis, show reduced sporulation on plants grown under $<380 \mathrm{~nm}$ blocking plastics (Honda, 1985; Honda et al., 1997, 1992; Honda and Yunoki, 1977; Sasaki and Honda, 1985). Plants grown under <380 plastics have also shown lower populations of several insect pests and lower incidence of insect-transmitted plant virus (Antignus et al., 1996, 1998; Costa and Robb, 1999) compared to the $<360 \mathrm{~nm}$ blocking plastics.

Received for publication 8 May 2000. Accepted for publication 29 Jan. 2001. We thank T. Pinckard, J. Virzi, S. Parker, K. Stringer, and the Mycotech Corporation for technical assistance. This research was funded in part by the Univ. of California Integrated Pest Management Program. The cost of publishing this paper was defrayed in part by the payment of page charges. Under postal regulations, this paper therefore must be hereby marked advertisement solely to indicate this fact.
Beauveria bassiana is an entomopathogenic fungus that has been used in several commercial formulations for control of insect pests, primarily aphids, whiteflies, and thrips. Ultraviolet radiation is one of the important factors affecting the survival of entomopathogenic fungi inocula (Fargues et al., 1986; Inglis et al., 1995; Jaronski and Goettel, 1997; Moore and Caudwell, 1997; Moreley-Davies et al., 1996). If the beneficial fungal spores could be protected from ultraviolet radiation, the increased survival of spores could increase the efficacy, reduce the cost of using these materials, and reduce the number of spray applications required. Inglis et al. (1995) demonstrated that the use of various UV-B protectants mixed with $B$. bassiana spores could increase spore survival under laboratory and field conditions, but only limited success was achieved.

The purpose of this study was to determine if greenhouse plastics designed to block transmission of UV light with wavelengths of 380 $\mathrm{nm}$ and below could be effective in increasing the persistence of viable spores from a commercial formulation of $B$. bassiana.

\section{Materials and Methods}

Experimental design. Greenhouse plastics that block transmission of UV light at different levels were selected from two manufacturers for use in the field studies. Two materials also had an infrared (IR) absorbing component in them designed to capture heat in the greenhouse without lowering the transmission of PAR. Three materials were selected for the field studies to get maximum comparative information: 1) a typical greenhouse plastic that blocks the transmission of UV light with wavelengths of $360 \mathrm{~nm}$ and below $(<360 \mathrm{~nm})$ (DuraGreen Marketing USA, Mount Dora, Fla.); 2) a plastic that blocks the transmission of UV light with wavelengths of $380 \mathrm{~nm}$ and below (<380 nm + IR) (DuraGreen Marketing USA, Mount Dora, Fla.); and 3) a plastic that blocks the transmission of UV light with wavelengths of $360 \mathrm{~nm}$ and below ( $<360 \mathrm{~nm}+$ IR) (Klerk's Plastic Products Manufacturing, Richburg, S.C.). The two $<360$ plastics were included to test if the presence of an IR component in the plastics would affect germination. All plastics were $6 \mathrm{~mL}$ thick.

Trials were conducted on a commercial cut flower production site located in San Diego, Calif. Nine hoop houses measuring $4 \mathrm{~m}$ wide $\times 8 \mathrm{~m}$ long $\times 3 \mathrm{~m}$ high were covered with one of the three plastics described above. A randomized complete-block design with three replications of each was used. Two beds (4 rows per bed, 15-20 cm spacing) of Golden Rod, Solidago sp., were planted in the ground in each house. Golden Rod was selected because it is a plant species the cooperator had previously grown under hoop house culture that typically has problems with pests that could potentially be controlled by Beauveria (aphids, whiteflies, etc.). Plant height averaged $60 \mathrm{~cm}$ during the experimental period. Mean high temperature under plastics at canopy height was $35.5 \pm 1^{\circ} \mathrm{C}$ and mean low was $6 \pm$ $0.5^{\circ} \mathrm{C}$

Application of material. A commercial formulation of $B$. bassiana Strain GHA, BotaniGard 22WP $\left(4.4 \times 10^{10}\right.$ spores/g; Mycotech Corp., Butte, Mont.) was selected for use in the study. Application rates were 1.3 $\mathrm{g} \cdot \mathrm{L}^{-1}$ for the first application, and $2.6 \mathrm{~g} \cdot \mathrm{L}^{-1}$ for the second and third applications. Applications were made one week apart on 7, 14, and $21 \mathrm{Dec}$. 1999. The material was applied at 13.8 $\mathrm{N} \cdot \mathrm{m}^{-2}$ using an electric pump tank sprayer (TeeJet TXVS-6 conejet; Spraying Systems Co., Wheaton, Ill.). The spray wand was equipped with a single hollow cone nozzle (TeeJet TXVS-6 conejet).

Fungal spore viability test. Benomyl yeast media (16 g Bacto agar, $0.5 \mathrm{~g}$ Bacto yeast extract, $0.1 \mathrm{~g}$ Tween $80,20 \mathrm{mg}$ Benlate 50WP per liter) was used to assay spore germination (Mycotech Corp., unpublished data). Agar plates were prepared by pouring autoclaved agar into sterile petri dishes (10-cm diameter) in a thin layer $(<5 \mathrm{~mm})$. Four leaf samples were collected from Solidago plants in each house on each sample date; leaf samples were taken from the middle of the plant. The upper sides of individual leaves were pressed onto the assay plates to transfer spores to the media.

Plates were incubated for 16-24 h at room temperature $\left(25\right.$ to $\left.27^{\circ} \mathrm{C}\right)$ to allow spore germination. Sections of agar $(2 \times 1 \mathrm{~cm})$ were cut from plates and placed on clean glass slides. To better visualize spores, a drop of lactofusion stain was added to the surface of the agar cube and covered with a cover slip. Agar sections were observed under a compound microscope at $\times 400$ magnification. The number of germinated and ungerminated spores was recorded, and the percentage of germina- 
tion calculated. Spores were considered germinated if swollen with germ tubes present or imminent. The minimum sample size was 50 spores per leaf. Germination was monitored 0 , 1,2 , and $6 \mathrm{~d}$ after the first application, 0, 2, 3, and $7 \mathrm{~d}$ after the second application, and 0,2 , 3,7 , and $13 \mathrm{~d}$ after the third application.

Light measurement. Readings of the relative amount of UV and visible light present in each greenhouse were taken on a sunny day at four locations through the length in each house and the mean value \pm SE per treatment reported. Light meters measured total UV light in the range of $250-400 \mathrm{~nm}$, and visible light in the range of 400-700 $\mathrm{nm}$ (models BQM and UVM, respectively; Spectrum Technologies, Apogee Instruments, Plainfield, Ill.).

Statistical analysis. Analysis of variance was performed on mean percentage of germination of spores and mean light measurements after appropriate transformations. Means were separated using Fisher's LSD (Minitab). Light levels were log transformed, and percentage of germination was square-root transformed before analysis.

\section{Results}

The $<380 \mathrm{~nm}+$ IR blocking plastic transmitted significantly less UV light than either the $<360 \mathrm{~nm}$ or $<360+$ IR plastic (Table 1). There was no significant difference between the $<360 \mathrm{~nm}$ and $<380 \mathrm{~nm}+$ IR plastics in the level of visible light transmitted. Although the $<360 \mathrm{~nm}+$ IR plastic transmitted significantly less UV and visible light than the $<360 \mathrm{~nm}$ plastic, the relative proportion of UV of total light transmitted was similar for both of the $<360 \mathrm{~nm}$ plastics.

First application. The percentage of spore germination under the different plastics after the first $B$. bassiana application was not significantly different $1 \mathrm{~d}$ after application (Fig. 1A). However, $2 \mathrm{~d}$ after application there was a significantly higher percentage of germination under the $<380 \mathrm{~nm}+$ IR blocking plastic compared to the $<360 \mathrm{~nm}$ plastic $(F=4.13$; df $=2,32 ; P=0.025)$. Six days after the first application, percentage of germination was twice as high under the $<380 \mathrm{~nm}+$ IR blocking plastic compared to $<360 \mathrm{~nm}$ plastic $(F=3.83$; $\mathrm{df}=2,33 ; P=0.032)$. Percentage of germination under the $<360 \mathrm{~nm}+$ IR plastic was higher than the $<360 \mathrm{~nm}$ plastic after $2 \mathrm{~d}(F=$ 4.13 ; df $=2,32 ; P=0.025)$, but not significantly different from $<360 \mathrm{~nm}$ at $6 \mathrm{~d}$ after application (Fig. 1A).

Second application. Spore germination after the second application was not significantly different at 2 or 3 days after application (Fig. 1B). At 7 days after application, percentage of germination was significantly higher under the $<380 \mathrm{~nm}+$ IR plastic compared to $<360 \mathrm{~nm}(F=13.5$; df $=2,32 ; P \leq 0.001)$. Percent germination under $<360 \mathrm{~nm}+$ IR and $<360$ nm plastics were not significantly different at any test date after the second $B$. bassiana application (Fig. 1B).

Third application. Percentage of germination after the third spray was not significantly different until $3 \mathrm{~d}$ after application. Germina-

Table 1. Ultraviolet and visible light readings under tested plastics.

\begin{tabular}{lcc}
\hline \hline Plastic & $\mathrm{UV}(250-400 \mathrm{~nm})$ & Visible $(400-700 \mathrm{~nm})$ \\
Treatment & $\mu \mathrm{mol} \cdot \mathrm{m}^{-2} \cdot \mathrm{s}^{-1}$ & $\mu \mathrm{mol} \cdot \mathrm{m}^{-2} \cdot \mathrm{s}^{-1}$ \\
\hline$<380 \mathrm{~nm}+\mathrm{IR}$ & $7 \pm 0.3 \mathrm{c}^{2}$ & $948 \pm 37 \mathrm{ab}$ \\
$<360 \mathrm{~nm}$ & $49 \pm 2 \mathrm{a}$ & $1020 \pm 52 \mathrm{a}$ \\
$<360 \mathrm{~nm}+\mathrm{IR}$ & $39 \pm 2 \mathrm{~b}$ & $834 \pm 61 \mathrm{~b}$ \\
\hline
\end{tabular}

${ }^{\mathrm{z}}$ Means in columns followed by the same letter are not significantly different $(P>0.05)$. Analysis of variance followed by Fisher's LSD separation of means.

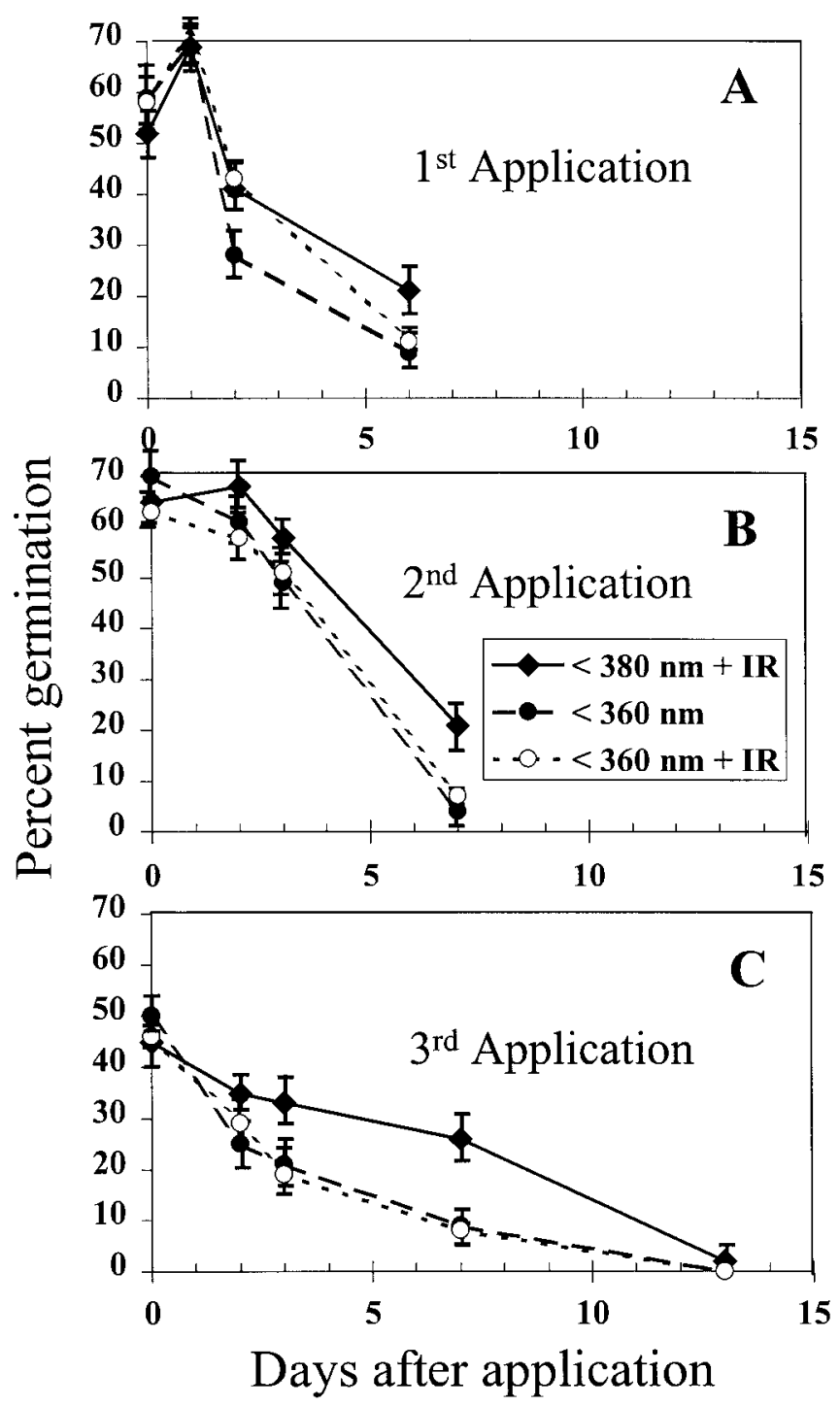

Fig. 1. Mean percentage of germination of Beauveria bassiana spores on plants grown under $<380 \mathrm{~nm}+\mathrm{IR}$ blocking, <360 nm blocking, or <360 nm + IR blocking greenhouse plastics at various times after each application. Means were compared among treatments at each date by analysis of variance followed by Fisher's LSD separation of means. Bars indicate SE of the mean.

tion was significantly higher under the $<380$ $\mathrm{nm}+$ IR plastic compared to the $<360 \mathrm{~nm}$ plastic at $3 \mathrm{~d}(F=3.27 ; \mathrm{df}=2,33 ; P=0.05)$ and $7 \mathrm{~d}(F=10.67 ; \mathrm{df}=2,33 ; P \leq 0.001)$ after application. Percentage of spore germination under the $<380 \mathrm{~nm}+$ IR plastic $7 \mathrm{~d}$ after application was similar to germination under the $<360 \mathrm{~nm}$ plastic at $3 \mathrm{~d}$ after application. Thirteen days after application, no germinated spores were observed on samples from the $<360 \mathrm{~nm}$ plastic houses, however, a low level of germination $(1.6 \%)$ was observed on samples from the $<380 \mathrm{~nm}$ houses (Fig. 1C). Germination under the $<360 \mathrm{~nm}+\mathrm{IR}$ and $<360 \mathrm{~nm}$ plastics was not significantly different at any test date after the third spray (Fig. 1C). The initial lower germination after the third spray likely resulted from the accumulation of nonviable spores on the leaves from the first and second applications. It was observed that the density of spores on the leaf impressions generally decreased over time, how- 
ever enough spores remained to be rated even at $13 \mathrm{~d}$ after application.

\section{Discussion}

The persistence of viable $B$. bassiana spores was increased under a greenhouse plastic that blocked transmission of UV light with wavelengths below $380 \mathrm{~nm}$ compared with plastics that blocked wavelengths below $360 \mathrm{~nm}$. One week after each $B$. bassiana application, percentage of spore germination was at least twice as high under the $<380 \mathrm{~nm}+$ IR blocking plastic compared to the $<360 \mathrm{~nm}$ or $<360 \mathrm{~nm}+$ IR plastics. These results indicate that the increased viability of spores was primarily the result of reducing the amount, the wavelength, or both, of UV light transmitted to leaves.

Increased spore viability increases the probability of contact of a viable spore by an insect pest when moving about the leaf surface several days after application. If the interval between applications could be increased, the amount of material applied and costs of using the materials would be reduced. Further studies are required to determine the impact of increased spore longevity on insect control.

\section{Literature Cited}

Antignus, Y., M. Lapidot, N. Mor, R. Ben-Joseph, and S. Cohen. 1996. Ultra violet absorbing plastic sheets protect crops from insect pests and virus diseases vectored by insects. Environ. Entomol. 25:919-924.

Antignus, Y., M. Lapidot, D. Hadar, Y. Messika, and S. Cohen. 1998. Ultraviolet-absorbing screens serve as optical barriers to protect crops from virus and insect pests. J. Econ. Entomol. 91:1401-1405.

Costa, H.S. and K.L. Robb. 1999. Effects of ultraviolet-absorbing greenhouse plastic films on flight behavior of Bemisia argentifolii (Homoptera: Aleyrodidae) and Frankliniella occidentalis (Thysanoptera:Thripidae). J. Econ. Entomol. 92:557-562.

Fargues, J., M.S. Goettel, N. Smits, A. Ouedraogo, C. Vidal, L.A. Lacey, C.J.Lomer and M. Rougier. 1996. Variability in susceptibility to simulated sunlight of spores among isolates of entomopathogenic Hyphomycetes. Mycopathologia 135:171-181.

Honda, Y. 1985. Control of seedling blast of rice with ultraviolet-absorbing vinyl film. Plant Dis. 69:596-598.

Honda, Y. and T. Yunoki. 1977. Control of Sclerotinia disease of greenhouse eggplant and cucumber by inhibition of development of apothecia. Plant Dis. Rpt. 61:1036-1040.
Honda, Y., T. Toki, and T. Yunoki. 1977. Control of gray mold of greenhouse cucumber and tomato by inhibiting sporulation. Plant Dis. Rpt. 61:1041-1044.

Honda, Y., T. Kashima, and T. Kumagai. 1992. Suppression of brown spot disease of cultivated chrysanthemum by manipulating phototropic response of conidium germ tubes of Septoria obesa. J. Phytopathol. 136:270-278.

Inglis, G.D., M.S. Goettel, and D.L. Johnson. 1995. Influence of ultraviolet light protectants on persistence of the entomopathogenic fungus, Beauveria bassiana. Biol. Cont. 5:581-590.

Moore, D. and R.W. Caudwell. 1997. Formulation of entomopathogens for the control of grasshoppers and locusts. Mem. Entomol. Soc. Can. 171:49-67.

Jaronski, S.T. and M.S. Goettel. 1997. Development of Beauveria bassiana for control of grasshoppers and locusts. Mem. Entomol. Soc. Can. 171:225-237.

Minitab Inc. 1996. Minitab reference manual, Release 11. Minitab, State College, Pa.

Morley-Davies, J., D. Moore, and C. Prior. 1996. Screening of Metarhizium and Beauveria spp. spores with exposure to simulated sunlight and a range of temperatures. Mycol. Res. 100:31-38.

Sasaki, T. and Y. Honda. 1985. Control of certain diseases of vegetables with ultraviolet-absorbing vinyl film. Plant Dis. 69:530-533. 